\title{
De Lanson à teoria do campo literário
}

\author{
JosephJurt \\ Tradução de Rodrigo Lacerda e Sergio Miceli
}

\section{As pesquisas literáriasna França}

A pós terminar meus estudos, obtive uma bolsa para compilar uma bibliografia dos trabalhos consagrados ao autor que fora tema de minha tese. Apresentei-me ao futuro editor em seu pequeno escritório ao pé da montanha de Santa G eneviève. Ele me examinou com algum ceticismo, para em seguida perguntar se minha formação era alemã ou francesa, o que me deixou em dificuldades. M eu professor de literatura francesa na U niversidade de Fribourg, na Suíça, era francês, o de filologia românica, italiano, e o de história medieval, austríaco. 0 que responder, então? Julguei estar agradando-o ao dizer que minha formação era francesa. Q ue pena, ele respondeu. Para um trabalho bibliográfico, a formação alemã é indispensável. É um trabalho de ourives. É preciso ser muito minucioso, não se perder em especulações.

Eu era e sou, de fato, um produto híbrido. Trabalhei alguns anos no espaço francófono; desde 1974 dou aulas naA lemanha. M eu olhar jamais é totalmente interior ou exterior. U ma visão panorâmica pressuporia um ponto de vista exterior ao campo. Esse nunca foi meu caso na A lemanha, e tampouco na França. Tal situação não é sempre confortável, mas pode contribuir para uma tentativa de objetivação. 0 lugar de meus primeiros estudos, a Suíça francesa, constituiu um espaço totalmente exterior; no 
decorrer de minha formação literária, em uma universidade da região, jamais ouvi referência al guma a um estudo de autor de língua alemã. $0 \mathrm{~s}$ dois espaços universitários, germanófono e francófono, por serem geograficamente muito próximos, davam- me a impressão de estarem lado a lado, sem que houvesse a menor comunicação. Sei que a comunicação é hoje em dia mais fácil, sem que haja um intercâmbio muito amplo. Por isso, talvez, o papel dos suíços seja um pouco o de atravessadores, o de retomar a tradição da H elvetia mediatrix (Jurt, 1991).

Pierre Bourdieu tinha-me pedido que fizesse uma apresentação em seu seminário sobre as pesquisas literárias na A lemanha, trabal ho publicado no número 78 da A ces de la recherche en sdiences sodales, sob o título " $D$ e I'analyse immanente à l'histoire sociale de la littérature" (Jurt, 1989); foime pedido que consolidasse um balanço similar para as pesquisas literárias na França. Este, que apresentarei aqui, será certamente parcial, marcado pela minha própria perspectiva, e está longe de ser exaustivo.

\section{Filologia e crítica literária}

A tradição alemã das pesquisas literárias está ligada ao conceito de filologia; ela se define por sua cientificidade, que, por sua vez, se liga a um relativismo histórico e a uma análise crítica de textos; naA lemanha, foi criado, desde 1842, o conceito de L iteraturwissenschaft (ciência da literatura), que se impôs e se opõe ao de L iteraturkritik (crítica literária). $\mathrm{N}$ a França (assim como na Itália ou na Espanha), o conceito de crítica literária engloba as pesquisas universitárias e 0 trabalho de jornalistas. $\mathrm{N}$ as obras francesas dedicadas à crítica literária, como a de Jean-Y ves Tadié

1. Ver também M ichel Jarrety (1988). (1967)1 ou outra organizada por Pierre Brunel (Brunel et al., 1977), tem-se por objeto exclusivamente a crítica profissional ou universitária, uma vez que o conceito equivalente na Alemanha (L iteraturkritik) remete apenas à crítica jornalística. Em uma obra publicada por Albert Thibaudet, que, embora tenha sido originalmente publicada em 1930, não deixou de ser pertinente, Physiologie de la aritique (1966), o autor distingue três tipos de crítica:

1. C rítica espontânea ou falada, outrora a dos salões, atualmente a dos jornais.

2. Crítica profissional, feita por especialistas cujo trabalho é ler livros e deles extrair certa doutrina comum. 
3. Crítica dos artistas, "feita pelos próprios escritores, quando refletem sobre sua arte".

Em resumo: na França, várias formas de abordagem da literatura estão englobadas sob o nome de crítica literária. A tendência é mais normativa que descritiva, servindo como referência o critério estético do gosto. $M$ ichael Werner definiu da seguinte maneira a diferença de estatuto (social e científico) entre a filologia alemã e a crítica literária francesa:

Ao adquirir o estatuto de ciência, a filologia coloca-se em posição dominante. C iência geral da cultura, ela compreende doravante a crítica literária, que perde sua autonomia. D isso resulta um divórcio entre a crítica universitária e a crítica literária de tipo jornalístico [...]. N a França, ao contrário, como se sabe, as trocas entre crítica literária e crítica universitária permanecem freqüentes [...]. As ciências sociaisse constituem em oposição às letras, arrogando-se precisamente o estatuto de ciência que elas, de outro lado, negam à pesquisa literária (1994, pp. 26-27).

$\mathrm{N}$ aAlemanha, o estatuto científico e profissional do professor de literatura reforça sua autoridade; na França, a autoridade do crítico está lastreada em sua função social. "O crítico literário, seja universitário ou não, cultiva o jardim do beletrismo. Ele deriva sua legitimidade não da profissionalização das carreiras universitárias, mas de seu pertencimento à escola culta, fundada sobre a cultura geral [...]" (Idem, p. 27).

\section{A tradição positivista na França}

As duas tradições, entretanto, não estavam separadas de forma categórica; houve, na verdade, intercâmbios entre uma e outra. Pois na França associamosa Lanson e à nova Sorbonne uma abordagem positivista e cientificista do fato literário. No debate público, essa concepção foi fustigada como uma importação alemã. A pós os anos 40 do século XIX , o método alemão de reconstrução filológica dos textos com base nos manuscritos foi introduzido na França, pondo em questão a forma deste ou daquele texto estabelecido. Esse método foi admitido após uma intervenção célebre deVictor Cousin sobre a tradição errônea em torno de um texto de Pascal:" [É preciso] estudá- lo por alguma via filológica" , escreveu C ousin, "pesquisar com uma curiosidade esclarecida as verdadeiras lições, as lições autênticas que o tempo e as mãos de editores inábeis apagaram pouco a 
pouco" (apud Espagne, 1990). M as na virada do século formou-se nos meios da crítica literária, em torno de Lemaître, Faguet, B runetière, $\mathrm{H}$ enri $M$ assiseAlfred deTarde, uma oposição muito forte a esse método. $M$ assise Tarde publicaram, em 1911, sob o pseudônimo deA gathon, o panfleto " 0 espírito da nova Sorbonne". Os dois autores viam nos métodos filológicos, assim como na sociologia de Durkheim, um ataque contra a cultura francesa clássica, uma forma sutil de subversão alemã:

Ah! 0 poderoso meio de expansão intelectual que é uma vitória! N inguém pensaria em colocar em dúvida que, mesmo tendo sido favorecidos pelo êxito militar, eram os procedimentos de cultura, 0 ensino, o próprio gênio dos alemães que haviam sobrepujado os nossos. E a filologia germânica foi considerada um agente de força nacional (M assis eTarde, 1911, p. 152).

Pelo conceito de filologia, os dois autores entendiam unicamente 0 estudo das fontese das filiações dos textos, que substitui ria agora as "idéias gerais" e o "gosto literário" . A intuição literária cederia lugar a uma acumulação de fichas; o espírito geométrico teria vencido o espírito de finesse. Essa recusa aos métodos da filologia alemã incluía também a sociologia de Durkheim, pedra fundamental da nova Sorbonne: "Essa sociologia apresenta um elemento básico e decisivo: o horror a tudo que é individual, a tudo que tem sua origem e seu fim no indivíduo, e o desprezo racionalizado por toda psicologia" (Idem, p. 154). Lanson ainda foi censurado por ignorar o papel do indivíduo criador, por exemplo de um Corneille, da mesma forma que parte do $\mathrm{C}$ id foi atribuída à influência de contemporâneos desconhecidos.

Durkheim de fato associara a literatura a uma espécie de período metafísico, pré-científico, e considerara a noção de indivíduo um obstáculo à apreensão racionalista da realidade. As ciências sociais afirmam, com Durkheim, uma pretensão universalista similar àquela da filologia na A lemanha - eis aí, ao menos, a aspiração da filologia na Antigüidade clássica - , a qual desejava abarcar o conjunto dos fenômenos culturais de uma época (Steinwachs, 1990, pp. 269-275). "Todos esses sistemas têm isso em comum", escreveu M ichael Werner,

[...] constituírem, cada um a sua maneira, revoltas contra a predominância cultural do fato literário na França. Desse ponto de vista, a "ciência social" à francesa tornou-se aliada da filologia "alemã". Ambas, na condição de "ciências", opu- 
nham-se à cultura do beletrismo e do gosto, à tradição retórica, ao "subjetivismo" literário. M as, ao mesmo tempo, distinguiam-se de maneira fundamental: a filologia leva ao extremo a historicização de seu objeto, a relativização das normas, enquanto a ciência social francesa permanece fundamentalmente nomotética, geradora de normas, ciência do "homem" [...]" (1990, p. 178).

M esmo que Lanson, convidado por D urkheim, tenha pronunciado em 1904, na Escola de Altos Estudos em Ciências Sociais, uma conferência que se tornaria célebre sobre "H istória literária e sociologia", não se deve reduzir a concepção de história literária de Lanson à ciência social de D urkheim. Como apontou com pertinência R émy Ponton, "há uma incompati bilidade entre os postulados éticos e teóricos da concepção durkheimiana do indivíduo e a ideologia da criação, que é um dos aportes intelectuais que a história literária de Lanson incorpora em sua própria definição" (1990, p. 259).

Lanson não estava tão longe dos métodos da crítica literária. Sua definição tolera a impressão subjetiva e a reação da sensibilidade pessoal. M as essa impressão deveria ser controlada pela pesquisa de fatores objetivos: "Todo o nosso método [...] é constituído para separar a impressão subjetiva do conhecimento objetivo, para limitá-la, controlála e interpretá-la em benefício do conhecimento objetivo" (Lanson, 1965, p. 53). Em um estudo sobre "O método da história literária", de 1910, Lanson chegou a afirmar: "O impressionismo é o único método que dá a sensação da energia e da beleza das obras" (Idem, pp. 39-40). 0 método histórico, o estudo do contexto literário e social das obras, as fontes, a crítica do texto, os estudos das influências deveriam reduzir o elemento puramente subjetivo da percepção literária. É preciso sublinhar aqui o fato de que Lanson evoluiu entre sua conferência de 1904 e seu texto de 1910. Em 1904, ele definira a literatura como um fato social total, estando a obra literária inserida numa rede preexistente de fontes e que contém uma imagem do público ao qual se dirige. Em 1910, ele insistirá sobretudo na particularidade da obra:

N ossas operações principais consistem em reconhecer os textos literários, em compará-los para distinguir o individual do coletivo e o original do tradicional, agrupá los em gêneros, escolas e movimentos, em determinar enfim a relação desses grupos com a vida intelectual, moral e social de nosso país, bem como com o desenvolvimento da literatura e da civilização européias (I dem, p. 43). 
Prensado entre a história e a sociologia, Lanson escolheu, segundo Paul Dirkx, "fazer da obra individual o objeto fundador que pertence exclusivamente ao estudo científico da literatura, pronto a reconhecer seu caráter parcialmente inapreensível" (2000, p. 61).

$\mathrm{N}$ o tocante à França, pode-se assim perceber um sistema de saber com três pólos, como bem soube mostrar Lepenies em seu livro $D$ ie drei $K$ ulturen (As três culturas): de um lado, as diências morais, entre as quais estão os homens de letras e os críticos literários; o primado conferido por eles à interpretação é, entretanto, contestado pelas ciências sociais, que se definem como as ciências do homem que têm por objeto os fenômenos culturais e sociais. 0 grande mundo (o universo biológico e físico) é 0 objeto das ciências naturais.

$\mathrm{N}$ a A lemanha configura-se, após Dilthey, um sistema com dois pólos: de um lado, as ciências naturais e, de outro, as ciências humanas ( $G$ eisteswissenschaften). Dilthey " reuniu as disciplinas que visam à interpretação do mundo àquelas que se concentram nas ordens vitais em uma unidade, destinada a superar ambos os domínios e separá-los da natureza" (Steinwachs, 1990, p. 273).

Se Lanson havia ainda praticado um ecletismo metodológico, seus epígonos reduziram a pesquisa literária à pura pesquisa de fontes, o que provocou uma esclerose na área, batizada de lansonismo positivista, predominante no interior do sistema universitário da França. As pesquisas literárias nesse país permaneceram, assim, bastante fechadas às inovações vindas do exterior, como por exemplo o formalismo russo, a crítica estilística alemã, o N ew C riticism norte-americano. Leo Spitzer constatou inclusive que não havia, antes de 1960, nenhuma autêntica teoria da literatura na França (Compagnon, 1998). N ão foi no interior da instituição, mas a partir de suas franjas, que se esboçou a inovação.

\section{A Escola de Genebra}

H ouve de início uma crítica extra-universitária que se definiu como "crítica criadora", ao recusar as pesquisas positivistas e ao conceber 0 ato de leitura como um encontro entre dois seres; seus representantes mais destacados foram Jacques $R$ ivière e $C$ harles $D$ u Bos. A valorização da intuição e da simpatia por B ergson havia, por sua vez, favorecido esse tipo de crítica.Tal espírito manifestou-se por meio da $\mathrm{N}$ ouvelle $\mathrm{R}$ evue $\mathrm{F}$ rançaise (N R F), fundada em 1909 e que reapareceu, desde 1919, concebendo-se 
como R évue de Littérature et $\mathrm{C}$ ritique, ao fundir criação e espírito crítico ou ao defender um classicismo aberto e hostil a um falso romantismo.

0 utro tipo de abertura em relação ao estreito sistema positivista universitário tomou forma na Suíça francesa, que não era dominada pelo sistema francês. Entre os pioneiros dessa nova crítica deve-se mencionar $M$ arcel $R$ aymond eA lbert B éguin. $O$ primeiro relatou que fora forçado, ao longo dos anos de 1930, quando da elaboração de sua tese A influência de R onsard na poesia francesa, 1550-1585, na Sorbonne, a pagar pedágio ao positivismo hegemônico e a relacionar as fontes como provas de uma influência.

O sdois críticos haviam sido inspirados por sua passagem pelaA lemanha. $M$ arcel R aymond fora professor de francês em Leipzig, entre 1926 e 1928, e Albert Béguin ensinara na U niversidade de H alle, entre 1929 e 1934.Tanto um como o outro não haviam sido iniciados no velho método filológico alemão. Pois nesse meio tempo surgira a $\mathrm{G}$ eistesgeschichte, segundo Werner K rauss uma resposta legítima perante a alienação positivista que ignorara a especificidade antropológica. U m método rígido e mecanicista emprestado das ciências naturais havia negligenciado a relação entre os materiais acumuladose a história humana.A revolução da história do espírito havia outra vez situado o homem no centro abandonado.

M ichael Werner explica essa mudança epistemológica inaugurada pela $G$ eistesgeschichte ao chamar atenção para o fato de que a tarefa da filologia, que se reduzia à materialidade "objetiva" do texto, à crítica textual e aos problemas de edição, devia um belo dia se esgotar. 0 lado normativo da filologia foi deslocado para a simples reconstrução de um passado histórico do qual não era mais possível extrair uma legitimidade nacional e cultural. A nova legitimidade passará por uma reativação da substância hermenêutica, de modo ostensivo sob a instigação de Dilthey (Werner, 1990, p. 168). A G eistesgeschichte significava uma ruptura com a antiga tradição filológica, ruptura que, entretanto, não tinha conseqüências no nível institucional. A disciplina continuava a ser designada pelo nome de filologia. São testemunhas dessa oscilação as observações sobre um título queViktor K lemperer e Eugen Lerch pretendiam dar a uma publicação anual dos suíços francófonos. Escrevem eles: "O conceito de filologia é hoje em dia duplamente suspeito: de um lado recende a educação primária, de outro invoca a ciência positivista da língua e da literatura que é para nós um fundamento incontornável, mas jamais um objetivo" (cf. Idem, p. 169). 
$R$ aymond e Béguin haviam se familiarizado, na Alemanha, com os métodos da $G$ eistesgeschichte representada por nomes como Dilthey, $C$ assirer e G undolf. A tarefa primordial da G eistesgeschichte era, segundo D ilthey, a de compreender e não a de explicar, como faziam as ciências naturais. Esses autores alemães pretendiam superar o positivismo sem recair num impressionismo científico. M arcel $\mathrm{R}$ aymond conta haver compreendido desde então que a obra de arte literária era, mais que uma acumulação de influências, um todo orgânico:

[...] fundo e formas são indissociáveis, o fundo está intricadamente implicado na forma. [...] Eu fiquei interessado, em grande parte sob a influência dos alemães que conheci entre os anos de 1926 e 1928, no grande movimento da cultura (falava-se ainda da $\mathrm{G}$ eistesgeschichte) e no que poderia haver aí de orgânico, num dado momento, como possibilidade e não como certeza, abarcando as diversas produções do espírito, a literatura, a pintura, a música etc. (R aymond, 1975, p. 81).

$R$ aymond havia encontrado este conceito - a saber, as diferentes formas de arte vistas como expressão do espírito - no historiador e filósofo da arte Dilthey (D as E rlebnis und die D ichtung), em G undolf (Shakespeare und der $D$ eutsche $G$ eist) e no historiador da arteW ölfflin, de quem traduziu os $\mathrm{G}$ rundbergriffe (C onceitos fundamentais da história da arte). A necessidade de apreender um núcleo central das obras, o qual se manifesta em formas específicas, leva a conceitos sintéticos como o de maneirismo em $M$ arcel $R$ aymond, 0 de barroco em Jean $R$ ousset, outro representante da Escola de Genebra, ou o de neoclassicismo em Starobinski (cf. DebrayGenette, 1990, p. 24).

Por ocasião de sua temporada em Halle, Albert Béguin teve de se defrontar com o romantismo como fenômeno global. Isso não o impediu de ser politicamente lúcido. Em seusartigos publicados no J ournal de G enève, esboçou uma imagem sem meios- tons da A lemanha nacional-socialista. Escreveu assim sobre um famoso discurso do reitor H eidegger em 1932, em Fribourg:

$\mathrm{N}$ ão saberíamos pôr o espírito na dependência de dados terrestres melhor que esse metafísico, a luta foi desencadeada aqui não apenas contra a ciência "estranha à vida", mas contra toda independência do pensamento e toda ambição de progresso pessoal (G rotzer, 1977, p. 46). 
Esse novo tipo de abordagem da literatura, resultante do encontro com a $G$ eistesgeschichte, levou a duas obras importantes, 0 livro D eB audelaire au surréalisme, publicado em 1933 por M arcel R aymond, e a tese L'âme romantique et le rêve, de A lbert Béguin, de 1937. 0 s dois autores atribuem ao sonho e ao inconsciente um papel central, sem considerá los, como Freud, um escape de materiais biográficos recalcados, mas um lugar portador de vestígios de uma unidade perdida para além da alienação ontológica e socioeconômica, e que seria reativada pela poesia. Béguin apresenta, sob esse ângulo, uma nova interpretação do romantismo alemão, ao identificar seus descendentes na França menos entre o romantismo oficial do que em $\mathrm{N}$ erval e R imbaud, cujas obras ele interpretava como busca metafísica dessa unidade perdida. Essa pesquisa implicava, para Béguin, diretor da E sprit após a guerra, um retorno ao mundo. Sua crítica, longe de ser puramente impressionista, era concebida como um ato intersubjetivo: "Penso", escreveu ele em 1958 na Esprit, "que a crítica mais valiosa é, apesar de tudo, a que está muito próxima de nossa escrita, isto é, na qual o escritor vive sua própria aventura ao escrever, e na qual, na invenção mesma das palavras, ele opera uma fase de sua aventura" ${ }^{2}$.

$\mathrm{N}$ o interior do sistema universitário suíço, relativamente liberal, $R$ aymond e Béguin puderam esboçar, o primeiro em Genebra, o segundo em Bâle, um novo tipo de abordagem literária. 0 s dois autores exerceram uma duradoura influência sobre uma segunda geração de universitários, que foi chamada de Escola de $G$ enebra. 0 straços característicos do grupo são bastante variados, mas, apesar de todas as diferenças, a abordagem temática foi apontada como traço comum. Para esses críticos, trata se de apreender os temas recorrentes nas obras literárias. Em R aymond, é 0 sentimento da existência como uma forma de consciência de si; em Starobinski, a relação de compreensão da consciência do outro; em Jean R ousset, a relação entre forma literária e vida do espírito; em Georges Poulet, as categorias da consciência: espaço, tempo, quantidade, causa. D evese incluir ainda nesse grupo Jean-Pierre R ichard e os primeiros trabal hos de R oland Barthes (M ichelet par lui-même). 0 sprocedimentostécnicosda análise textual não são jamais, para esses autores, um objetivo, mas um meio para um encontro pessoal entre a consciência crítica e a consciência criadora ou, para dizer como Starobinski:"Se fosse preciso descobrir neles um traço comum, seria este: a subordinação das técnicas (filológicas, gramaticais, descritivas) a uma visão pessoal, de natureza tanto religiosa (B éguin, $R$ aymond) como estética ou, ainda, antropológica" (1975, pp. 89-90).
2.Ver também Guissard (1983, pp. 30-31). 
0 representante da Escola de Genebra de maior presença em nossos dias, sem dúvida, é Jean Starobinski, cujas obras críticas se distinguem por uma el egância e uma originalidade desprovidas de qual quer jargão. D otado de formação científica, ele se diferencia pela utilização freqüente de procedimentos heurísticos e descritivos, procedentes das ciências médicas e humanas. M as essas descrições constituem, como afirma Claude $R$ eichler (1987), uma base de trabalho, jamais um objetivo, e servem apenas para lastrear em fatos verificáveis o impulso da interpretação sempre subjetiva e arriscada. Entre os mestres com os quais aprendeu, Starobinski menciona $\mathrm{R}$ aymond e Poulet, $\mathrm{C}$ assirer, Freud, Spitzer e Sartre.

\section{A abordagem sartriana}

À primeira vista, é possível haver alguma surpresa ao encontrar Sartre entre os mestres da crítica literária. M as é absolutamente imprescindível mencioná lo aqui. Pois Sartre é um exemplo típico da crítica literária francesa, que não se restringe à instituição universitária. A nna Boschetti (1985) mostrou o quanto ele dominou por completo o campo intelectual entre 1945 e 1960, ao aliar as funções do filósofo, do dramaturgo, do romancista e do crítico literário.

Sartre alia de fato as três funções do crítico identificadas por T hibaudet. D e início ele praticou a crítica espontânea, a crítica do livro do dia, por meio de seus artigos, artigos- programa, artigos de circunstância, chegando no mais das vezes à composição de retratos, artigos de comentário, que tomavam uma obra contemporânea como objeto de estudo, críticas que impressionam sempre por sua atualidade e que serão reunidas nos quatro volumes de Situations (Sicard, 1976, p. 8). Em seguida, praticou a crítica dos profissionais, não tanto como especialista em literatura, mas como filósofo que não se apega apenas a uma obra em particular, mas que percebe as regras de constituição. E por fim Sartre praticou a crítica dos artistas ou dos mestres, feita pelos próprios escritores. Três mil páginas constituem sua obra crítica, com destaque para os textos sobre Baudelaire, Flaubert, $M$ allarmé e $G$ enet. Ao acumular essas três funções, ele exercerá uma autoridade incontestável, que pôde fazer calar, quando necessário, um romancista estabelecido como François $M$ auriac. Do alto de sua tripla autoridade, Sartre critica a crítica literária tradicional, que fazia da literatura uma série de textos mortos, "pequenos caixões que dispomos sobre pranchas, ao longo dos muros, como urnas de um columbário" 
(Sartre, 1948, pp. 77- 78). A s incursões críticas, na feliz expressão de A nna Boschetti,

[...] são um instrumento poderoso graças ao qual Sartre desentulha o campo em torno de si e ao mesmo tempo trabalha, em surdina, no sentido de definir e legitimar sua posição. N ão se trata de um projeto consciente, é claro. Por meio dessas análises, ele visa a explicitar e organizar uma teoria do fato literário (1985, p. 63).

Essa teoria, essa crítica literária, al go que se revela outra vez típico do universo institucional francês, distingue-se por sua forte dimensão normativa, que em Sartre se evidencia no conceito de uma literatura engajada: "O escritor 'engajado' sabe que a palavra é ação: sabe que revelar é mudar e que não se pode revelar sem que o intuito seja mudar. Ele abandonou o sonho impossível de fazer uma pintura imparcial da sociedade" (Sartre, 1946, p. 30). Essa exigência de uma literatura engajada o conduz a distinguir com nitidez a prosa da poesia. As palavras da poesia são como a música, a pintura e a escultura, coisas que remetem a elas mesmas, e deixam de ser signos ou instrumentos. A prosa, ao contrário, é transitiva; ela é instrumento de uma empreitada que tem um objetivo. Essa dissociação permitiu a Sartre conservar uma concepção bastante autônoma da arte reservada à poesia, enquanto defendia uma arte instrumental, função que reservava à prosa. Essa arte engajada visa à ação e, por seu intermédio, ao leitor; a escrita é assim um apelo à liberdade do leitor. "Para quem escrevemos?" é, portanto, uma pergunta importante para Sartre. A obra contém a seus olhos sempre uma imagem do público visado. "O meio é um vis a tergo; 0 público, ao contrário, é uma expectativa, um vazio a preencher, uma aspiração, no sentido figurado e no literal, em suma, é o outro" (I dem, p. 96). A recepção desempenha, assim, um papel capital para ele, o qual estará no centro da estética da recepção desenvolvida na Alemanha após o fim dos anos de 1960, sem que se tenha reconhecido Sartre como um predecessor. Para ele, a obra de arte é um apelo à liberdade do leitor, não a liberdade de criar o novo, mas a liberdade de recompor. 0 leitor é assim indispensável ao autor. Este escreve para criar um objeto em relação ao qual possa se sentir essencial e não contingente. É preciso, portanto, que a obra deixe o domínio da subjetividade do autor. Ao responder ao apelo que 0 autor Ihe lança por meio da obra, o leitor a percebe e a cria ao mesmo tempo, o que permite ao autor sair de sua contingência. $M$ as o leitor é igualmente indispen- 
sável por ser quem realizará o apelo de transformar o mundo que the lança 0 autor (Galster, 1986, p. 5).

Contudo, a explicação do fato literário a partir do meio de origem, a concepção da literatura como expressão de uma classe social, predominou no interior de uma teoria literária de inspiração marxista. Sartre não podia se eximir de tomar posição em relação a essa concepção.Todas as abordagens da literatura empenhadas em inserir o fato literário em um conjunto mais global são na verdade levadas a se interrogar sobre o sujeito, ou o suporte, da criação literária.

D esde o fim dos anos de 1950, Sartre havia criticado, em Q uestions de méthode, a insuficiência heurística de um método marxista que se prendia apenas à dimensão econômica, categoria universal e abstrata, como determinante da produção cultural, negligenciando assim toda uma hierarquia de mediações concretas. A particularidade de uma obra literária é, segundo tal abordagem, um mero efeito do acaso, pois o que se leva em conta nesse método são apenas categorias de explicação vinculadas, segundo Sartre, a um universalismo abstrato. 0 autor de $Q$ uestions de méthode traduziu muito bem o impasse dessa explicação: "Valéry é um intelectual pequeno- burguês, disso não há dúvida. $M$ as nem todo intelectual pequeno-burguês é umValéry" (Sartre, 1967, p. 80). Sartre via o mesmo tipo de universalismo abstrato em uma interpretação marxista capaz de afirmar que "o realismo de Flaubert guarda relação com a evolução social e política do Segundo Império" (I dem, p. 82). Essa abordagem apega-se a tamanha generalidade sem explicar a gênese dessa reciprocidade de perspectiva, sem responder por que ele preferiu a literatura a qualquer outra coisa, e nem por que escreveu esses livros, em vez dos escritos por D uranty ou pelos G oncourt. A especificidade da vida e a da pesso a não são elucidadas. Flaubert é burguês porque nasceu na burguesia. $M$ as não é nem a renda patrimonial nem a natureza intelectual que fazem dele um burguês. "É portanto na particularidade de uma história, por meio das contradições próprias daquela família, que G ustave Flaubert fez obscuramente 0 aprendizado de sua classe [...] o menino tornou-se isso ou aquilo porque viveu o universal como particular" (Idem, p. 83). Para Sartre, um princípio de explicação importante da especificidade de uma obra literária deve ser buscado nas impregnações sofridas pelo indivíduo na infância:

A mistura explosiva de cientificismo ingênuo e religião sem D eus que constitui Flaubert, e que ele tenta superar pelo amor à arte formal, pode ser explicada 
[pensa Sartre] se compreendemos bem que tudo se passou na infância, isto é, em uma condição radical mente distinta da condição adulta: é a infância que molda os preconceitos insuperáveis, é nela que se experimenta, nas violências do adestramento e no extravio da criatura selvagem domada, o pertencimento ao meio como um evento singular (I dem, p. 85).

Por essa razão, Sartre pensa que a psicanálise é um instrumento adequado para apreender no adulto "o peso de sua história" (Idem, pp. 85-86). 0 existencialismo pode integrar o método psicanalítico, pois permite pensar "a família singular como mediação entre a classe universal e o indivíduo" (Idem, p. 88).

Sartre compara Flaubert e Baudelaire, nascidos no mesmo ano, e explica a especificidade de suas obras por meio de diferenças sociológicas e psicológicas. Flaubert é fruto de uma burguesia inculta e emergente, enquanto $B$ audelaire vinha de uma antiga família burguesa urbana. Flaubert caracteriza-se por uma fixação pelo pai, ao passo que Baudelaire tem fixação pela mãe. Será preciso tentar levar em conta as duas dimensões, o que seria possível à psicanálise tal como Sartre a concebe, ela que "remete de um lado às estruturas objetivas, às condições materiais, e, de outro, à ação de nossa incontornável infância sobre nossa vida adulta" (I dem, p. 90).

$\mathrm{N}$ ão se poderia, portanto, ligar uma obra como M adame B ovary exclusivamente à estrutura político-social e à evolução da pequena burguesia: "Será necessário conectar a obra à realidade presente na medida em que ela é vivida por Flaubert por meio de sua infância" (Idem, ibidem). A ssim, a obra não remete apenas a um momento específico, à época contemporânea imediata, mas também a outras camadas temporais que estão ligadas à situação familiar, que pode estar avançada ou atrasada em relação à sua época. Sartre fala de um tipo de histerese da obra (um atraso do efeito em relação à causa) no tocante à época em que ela aparece, o que é específico dos eventos contemporâneos, que sempre se caracterizam pela

[...] extraordinária diversidade de sua profundidade temporal: Flaubert parecerá à frente de sua época (quando escreveu M adame B ovary) porque estava atrasado em relação a ela, porque sua obra exprime veladamente, a uma geração desgostosa com o romantismo, os desesperos pós românticos de um colegial de 1830 (Idem, p. 91).

Em suma, Flaubert consuma a "união paradoxal de dois momentos passados dessa pequena burguesia intelectual (1830-1845)" (Idem, ibidem). 
H averia, por essa razão, duas dimensões na obra de Flaubert: uma visão pessimista, que osjovens leitores, envergonhados pelo fracasso de sua revolução em 1848, buscavam acima de tudo, e uma contrapartida positiva, um misticismo estético que somente um Baudelaire sabia perceber.

\section{0 estruturalismogenético}

Com base num marxismo dialético, Lucien Goldmann tentou, na condição de crítico literário, elucidar o problema do verdadeiro sujeito da criação literária, notadamente em seu livro L e D ieu caché, publicado em 1955.

N os passos de Lukács, ele também pretendia explicar geneticamente as obras literárias. 0 verdadeiro sujeito da criação literáriaé, para G oldmann, o grupo social - critério de explicação mais objetivo que o do sujeito individual; a seus olhos, a estruturação da unidade coletiva é mais simples e mais coerente que a da psicologia dos indivíduos. 0 grupo social elabora em seu meio "tendências afetivas, intelectuais e práticas, dando uma resposta coerente aos problemas suscitados por suas relações com a natureza e por suas relações inter-humanas" (Goldmann, 1964, p. 346), ou seja, os elementos de uma visão de mundo. Astendências da consciência coletiva são condicionadas, por sua vez, por uma dada situação social, política, econômica; pensamentos similares no nível da consciência - o calvinismo e o jansenismo, por exemplo - ganham especificidade apenas em seus prolongamentos na vida social e econômica. 0 pensamento incompletamente formulado no grupo social atinge uma coerência eficaz nas grandes obras culturais, cuja estrutura é homóloga às estruturas mentais do grupo. A consciência coletiva, lugar de elaboração da visão do mundo, constitui assim um elo mediador essencial entre as manifestações literárias e a vida econômica, social e política.

N a obra mestra de Lucien Goldmann, Le D ieu caché, a estrutura trágica do teatro raciniano e do Pensées de Pascal é, portanto, interpretada como a expressão da visão de mundo elaborada pela consciência coletiva, no caso 0 jansenismo extremista, como expressão ideológica da nobreza de toga. A situação de classe dessa nobreza só pode ser explicada por sua inserção numa sociedade global, na qual ela se diferencia tanto da burguesia como da nobreza de espada. C ada uma dessas estruturas é, em si mesma, significativa, mas cada uma nasce de uma totalidade mais ampla. Goldmann não negligencia 0 aspecto "antecipatório" de um pensamento. 0 de Pascal, por exemplo, é apresentado por ele, "quando trata do mundo atual 
(epistemologia, estética, teoria da vida social), como uma etapa bem avançada no caminho que vai do individualista racionalista e cético ao pensamento dialético" (Goldmann, 1971, p. 290).

Q uando G oldmann se lançou no estudo do romance contemporâneo, pôde constatar uma homologia entre a obra literária e a estrutura socioeconômica, mas não conseguiu identificar um esquema análogo em rela ção à consciência coletiva. Essa ausência de mediação justifica-se, segundo ele, pelo processo de reificação que tornou implícitososvalores expressos na arte moderna. Com essa explicação ele de fato dissimulou o caráter não universal do conceito de visão de mundo. Também já se pretendeu censurar nesse conceito 0 descarte da especificidade literária, na medida em que uma visão de mundo poderia ser expressa tanto por uma grande obra filosófica como por uma obra literária. E ainda houve quem pensasse que esse estruturalismo genético operava de maneira reducionista. Christophe $\mathrm{C}$ harle lembrou que a homologia não é forçosamente uma categoria muito pertinente de explicação:

0 social é tanto 0 diferente quanto o homólogo, sobretudo no que diz respeito aos intelectuais e aos escritores. [...] Ser jansenista não é ser um burguês de toga como os outros, e escrever tragédias, ou o P ensées, não éigualmente ser um jansenista como os outros" (C harle, 1979, p. 23).

Se Lucien G oldmann chamou sua abordagem de estruturalismo genético, foi por ter utilizado o conceito de "estrutura significativa", empresta do aliás de Hegel e de Lukács; o termo "genético" remetia entretanto à $H$ istória, que os verdadeiros estrutural istas colocavam entre parênteses. $A$ questão fundamental de Goldmann foi a do sujeito da criação literária, noção que será declarada obsoleta pelo estruturalismo. Com a crítica literária estruturalista de inspiração lingüístico-semiótica, outra escola de $\mathrm{Ge}$ nebra servirá de referência, não mais aquela que, com Béguin e R aymond, definia $o$ ato crítico como um encontro intersubjetivo, mas a que se inspira em Saussure, ao distinguir claramente entre língua e palavra; essa nova crítica definirá a literatura à semelhança da língua, como um sistema objetivo do qual é preciso depreender uma gramática.

\section{Teoria das formas literárias}

Essa mudança de paradigma é fácil de datar. Se Jean-Paul Sartre, com sua filosofia do sujeito e da consciência e seu conceito de literatura 
engajada, dominou o campo intelectual após 1945, pode- se constatar uma virada que começa no final dos anos de 1950 e vai até o início da década seguinte; é o paradigma das ciências humanas que se impunha e que foi desde logo percebido sob a denominação de estruturalismo. Em 1958, C laude Lévi-Strauss publicou sua A nthropologie structurale; um ano antes foram lançadas as M ythologies de R oland Barthes e, em 1961, M ichel Foucault publicou $\mathrm{H}$ istoire de la folie. $\mathrm{Claro}$, as abordagens desses pensadores eram diferentes, mas havia, entretanto, pontos em comum; a H istória como categoria explicativa havia sido eliminada, bem como 0 sujeito. 0 historiador M ichel W inok referiu-se ao "refluxo do 'pensamento engaja do', que dominara a vida intelectual depois da Libertação", e vai além descrevendo assim a mudança:

Assistiu-se, pois, a retornar, com força, um cientificismo restaurado, orgulhoso, que desprezava a filosofia do sujeito e que, a partir da lingüística, invade o conjunto das ciências humanas e sociais, com o título intimidador de "estruturalismo". Alguns nomes estavam em todas as bocas, referências supremas da nova cientificidade: Lévi-Strauss, Lacan, Foucault... Todos, à sua maneira, devolviam o sujeito consciente e a evolução histórica à condição de aparências, sob as quais eles des nudavam estruturas objetivas até aquele momento ocultadas ao comum dosmortais (W inock, 1987, pp. 48-49).

Anna Boschetti mencionara as condições sociais e políticas que podiam explicar a mudança de paradigma. Ela apontara a recuperação econômica, a consolidação do gaulismo, o fim da guerra daA rgélia, o ocaso da Guerra Fria, o desmoronamento do comunismo utópico, destituído, após Budapeste, de seus mitos mobilizadores; tudo isso teria levado a destronar o profetismo existencialista, que era um produto da crise, dosproblemas da sociedade e da tensão internacional do pós-guerra.

O stempos são propíciosa uma nova filosofia social, otimista, que tende a conferir aos mecanismos econômicosuma tendência intrínseca à racionalidade e a acreditar que a ciência, melhor que a política, pode facilitar o progresso automático que a modernização parece prometer (Boschetti, 1985, p. 300).

Com a dita reorientação estruturalista, por volta de 1960, a concepção sartriana do sujeito, assim como o postulado normativo de uma "literatura engajada" foram questionados radicalmente. A norma literária, sem 
dúvida, tem um impacto sobre as abordagens da literatura. A predominância das ciências humanas não deixou de ter conseqüências sobre os métodos da crítica literária. U ma tendência formalista de abordagem literária abria diante de si o caminho que não mais se preocupava com a categoria do sujeito, fosse ele individual ou coletivo.

É impressionante que a Alemanha tenha conhecido na época uma situação inversa. 0 paradigma literário dominante após a guerra fora a abordagem imanente, cujo fim era apreender a obra literária nela mesma, pedindo-Ihe que fornecesse as chaves de compreensão e dispensando por completo a biografia, a história literária e a história propriamente dita. As noções fundamentais da poética, isto é, as de gênero, foram assimiladas a categorias antropológicas trans-históricas. N essa época, naA lemanha, concomitante com tal abordagem, surgiram muitos estudos so bre os aspectos da técnica literária que tinham a ver com a narratologia. As pesquisas sobre a técnica narrativa avizinhavam-se da abordagem "antropológica" graças ao fato de que essas categorias também permitiam apreender a obra nela mesma, sem fazer intervir a dimensão histórica. $\mathrm{N}$ o início dos anos de 1960, entretanto, podia-se constatar na A lemanha uma mudança de orientação dos estudos literários: a dimensão histórica será cada vez mais levada em conta, enquanto começam a despontar tendências rumo à história social (Jurt, 1989).

$\mathrm{N}$ a França, ao contrário, é uma teoria das formas literárias que emerge, notadamente em $\mathrm{R}$ oland Barthes e $\mathrm{G}$ érard $\mathrm{G}$ enette. $O$ s estudos narratológicos desenvolvidos na Alemanha do pós-guerra, como as análises de Günter M üller sobre a relação entre os tempos da narrativa e da história, as de $\mathrm{K}$ äte $\mathrm{H}$ amburguer, Wolfgang $\mathrm{K}$ ayser e Stanzel, sobre as instâncias narrativas, serão os únicos estudos alemães a serem citados nas pesquisas narratológicas francesas, por exemplo em Figures III, de G enette, que reunira os estudos publicados antes de 1966 no série intitulada F igures. N um dos textos desse volume, intitulado "Estruturalismo e crítica literária", ele falou da "vocação estruturalista" da crítica literária, que deveria se organizar em um verdadeiro método estrutural, agora sob orientação de ciências humanas como a lingüística ou a antropologia. Genette referia se em especial a Lévi-Strauss. 0 método estrutural revelar-se-ia particularmente fecundo no momento em que a crítica deixa de analisar as condições de existência da obra, ou os determinismos psicológicos, ou os sociais, para considerá-la "um ser absoluto" (Genette, 1966, p. 156). A simpatia de Genette incide decerto nessa abordagem quando ele afirma que a histó- 
3. G enette refere-se nesse contexto ajakobson: "A teoria lingüística estrutural, como a mecânica quântica, ganha em determinismo mórfico o que perde em determinismo temporal" (1963, p. 74). ria "historicizante", a ilusão biográfica e o positivismo haviam saído de moda. A análise estrutural poderia ser considerada um equivalente do que osnorte-americanos chamavam de dose reading ou os europeus, no linguajar de Spitzer, de estudo imanente, ao tratar as obras como organismos poéticos em si, sem nenhuma atenção para a psicologia do autor. Esse tipo de análise poderia garantir ao estudo imanente uma racionalidade de compreensão, em lugar da racionalidade de explicação (por meio da pesquisa das causas). U m determinismo espacial tomaria o lugar do determinismo temporal da gênese, enquanto os termos de filiação dariam vez aos de relação (cf. I dem, pp. 156-157)3. Essa análise estrutural permitiria captar o domínio etnográfico da literatura, inacessível a uma participação intersubjetiva, que estaria afastada de nós no tempo ou no espaço.

Em F igures III, de 1972, Gérard Genette definiu ainda mais energicamente sua abordagem como uma teoria das formas literárias, uma poética. Por meio dessa designação, pretendia inscrever-se na tradição secular que vai de Aristóteles a La H arpe, interrompida em alguma medida pelo romantismo, que deslocou a atenção das formas e dos gêneros para os "indivíduos criadores". D esde então, de Sainte-Beuve até nossos dias, assistiu-se ao apego a uma psicologia da obra, numa variação de perspectivas - histórica, psicanalítica, sociológica, marxista - , ora se voltando para o autor ora para o leitor; não obstante, a função essencial da crítica permanecerá sempre a de "estabelecer o diálogo de um texto com uma psique, consciente e/ ou inconsciente, individual e/ ou coletiva, criadora e/ ou receptora" (Genette, 1972, p. 10).

0 texto não seria mais analisado em sua lógica interna, mas em relação a um pólo constitutivo exterior a ele. G enette não identifica mais aqui sua abordagem à imanência da obra. N ão se trata mais da obra singular, mas de dados transcendentes, relativos à lingüística, à estilística, à semiologia, à análise dos discursos, à lógica narrativa, à temática dos gêneros. Pelo viés dessas categorias, e transcendendo a obra particular, constituir-se-ia"uma teoria das formas literárias, digamos uma poética" (I dem, ibidem).

A abordagem de Genette pretendia, assim, definir-se por seu caráter científico, imagem distintiva das ciências humanas; 0 termo "poética" sugeria ainda uma continuidade a partir das primeiras abordagens da litera tura que datavam da A ntigüidade. A poética não é mais definida, como no período clássico, por sua dimensão normativa, que tranfforma em norma a tradição.Trata se antes de explorar as diversas possibilidades do discurso, em cujo âmbito as obras escritas ou a escrever constituem tão-somente 
realizações particulares, sendo sempre possíveis outras combinações. A o sublinhar o caráter aberto da poética, Genette quis evitar uma eventual censura de passadismo; com alguma ênfase, ele escreveu assim: "A teoria literária [...] será moderna, e ligada à modernidade da literatura, ou não será nada" (Idem, p. 11).

A teoria das formas literárias exclui radicalmente 0 sujeito individual ou coletivo como categoria de explicação. Ela não se define mais como uma abordagem histórica num sentido tradicional. G enette caracteriza a teoria das formas literárias como "uma colocação entre parênteses provisória, uma suspensão metódica" da H istória (I dem, p. 13). Sobre as obras literárias em sua textualidade, e não mais em sua gênese e difusão, não poderíamos dizer nada em registro diacrônico. A crítica literária "não pode ser histórica, pois ela se consuma sempre numa relação direta de interpretação [...] entre o crítico e a obra, e essa relação é essencialmente anacrônica [...]" (Idem, pp. 17-18)4.

Genette refere- se aqui ao importante estudo de R oland Barthes, " $\mathrm{H}$ istória e literatura", publicado em 1960 na revista A nnales e retomado na obra Sur R adine. $N$ ele Barthes defende a tese da impermeabilidade entre a história geral e as obras: “ 0 mundo, sua pletora de fatos políticos, sociais, econômicos, ideológicos", não tem nada a ver com "a obra de aparência solitária, sempre ambígua, pois se presta ao mesmo tempo a várias significações" . O s dois continentes não são complementares, as formas resistem e não mudam no mesmo ritmo (Barthes, 1960, p. 524). A s histórias literá rias tradicionais seriam apenas sucessões de retratos de autor. A obra não seria passivel de história, ela lhe escaparia de al gum modo. Barthes estabeleceu assim uma dicotomia entre a literatura como instituição engendra da na história e a literatura como criação, ancorada na psicologia. "A história não nos dirá jamais o que se passa com um autor no momento em que ele escreve", afirma (Idem, p. 526). A história literária deve, por essa razão, restringir-se ao estudo da "função literária" , "o meio" , a formação intelectual do público e seus autores, os fatos da mentalidade coletiva, os fatos literários institucionalizados, como a retórica ou a história da idéia de literatura. A os olhos de Barthes,

[...] portanto, é apenas no nível das funções literárias (produção, comunicação, consumo) que a história pode se situar, e não no nível dos indivíduos que exerceram tais funções. Dito de outro modo, a histórialiteráriasó é possível quando se faz sociológica, se se interessa pelas atividadese pelas instituições, não pelos indivíduos" (I dem, p. 530).
4. M ais tarde afirmará que a crítica, ao se fechar na" imanência do texto", parecerá freqüentemente ameaça da de asfixia. Por essa razão ele teria optado pela transtextualidade, isto é, pela hipertextualidade, que é o tema de Palimpsestes ou que está no centro de Seuils. M as trata-se sempre, com certeza, de um universo textual. Ver Genette (1983, pp. 40-41). 
É preciso, pois, amputar da literatura a dimensão histórica do indivíduo. A obra prende-se ao indivíduo e a esse respeito afirmações objetivas são inconcebíveis; e assim Barthes encarrega o crítico de anunciar seu sistema de leitura, "não havendo, bem entendido, nenhuma neutralidade nessa matéria” (Idem, p. 537).

R econhecer essa impotência em dizer a verdade sobre R acine é, precisamente, reconhecer enfim o estatuto especial da literatura. 0 que há é um paradoxo: a literatura é esse conjunto de objetos e regras, de técnicas e de obras, cuja função naeconomia geral de nossa sociedade é precisamente institucionalizar a subjetividade (Idem, p. 536).

R oland Barthes considera Lucien Goldmann aquele que construiu a "teoria mais avançada daquilo que se pode chamar de crítica da significa ção" (I dem, p. 531); percebe nele a vontade de ligar mundo e obra, o institucional e 0 individual.

M esmo Goldmann, tão cuidadoso em multiplicar os ligamentos entre a obrae seu significado, cede ao postulado analógico: Pascal e R acine pertencem a um grupo social politicamente desalentado, e sua visão de mundo reproduzirá tal desalento, como se o único poder do escritor fosse se autocopiar (Idem, p. 535).

Barthes postula assim para as obras um estatuto de "exterritorialidade" histórica e social. Ainda que se recuse um olhar simplesmente mimético ou analógico entre o texto e o contexto, não se saberia negar a presença do social na própria obra, uma presença que pressupõe métodos mais sutis, ao permitir captá-la em sua especificidade.

\section{A crítica genética}

No interior dessa teoria das formas literárias, a noção de obra foi substituída pela de "texto", elaborada por R oland B arthes e Julia K risteva. 0 texto é considerado um sistema fechado, auto-suficiente, no qual é preciso analisar as estruturas e as funções. Se a poética estrutural havia-se interessado exclusivamente pelos sistemas e pelas funções das formas, atendo-se ao estrito fechamento do texto, desde o início dos anos de 1970 começou-se a introduzir o que L ouis $\mathrm{H}$ ay chamou de terceira dimensão do texto, isto é, a relação que as obras modernas mantêm com sua própria 
temporalidade de ocorrência, ao se estudar o processo gerador por meio de uma análise dos manuscritos.

Assim se constitui a crítica genética. A pós a obsessão sincrônica pela forma, surgiu o interesse pelo desenrolar diacrônico. Essa evolução já se fazia anunciar nos últimos escritos de R oland Barthes; por exemplo, em seu artigo sobre a"teoria do texto", que veio à luz em 1985, na E ncydopedia universalis, ele já admitia também a historicidade genética interna ao texto. Esse novo tratamento teve início em 1977, com o livro de Jean Bellemin$N$ oël, L e tex te et l' avant-texte, o qual, por meio da análise de esboços de um poema de M ilosz, defendia uma "poética de rascunhos". Enquanto mantinha uma teoria estrutural do texto, ele se concentrou na textualidade espaço-temporal, sem recorrer, entretanto, a um sujeito produtor ou receptor. A crítica genética constituiu daí em diante um paradigma importante das pesquisas literárias na França.

A genética textual, ao reivindicar a teorização de uma dimensão histórica, no interior mesmo do texto, como sublinha com propriedade Pierre$M$ arc de Biasi, introduziu assim "o que mais fazia falta às análises formais: a extensão inexplorada de um novo objeto estruturado pelo tempo" (Biasi, 1985, p. 468).

A crítica genética procurará definir, segundo Jacques N eefs, " nos está gios sucessivos ou concorrentes de um conjunto de escritos, as relações significativas de uma atividade criadora, e elaborar uma'poética' da escrita" (1990, p. 22). R aymonde D ebray-G enette definiu muito bem o verda deiro objetivo de uma crítica genética, que deveria ser mais que uma simples coadjuvante para a crítica moderna e chegar a" construir uma poética específica dos manuscritos, que seria tal vez al guma coisa como uma poética da escrita em oposição a uma poética do texto" (1979, p. 24). Essa análise do processo de escrita e de sua dinâmica interna deve ser diferenciada de uma abordagem que parte do texto final e que procura nos rascunhos somente uma explicação ou uma verificação de elementos estilísticos, estruturais, temáticos, legíveis no texto acabado. Pierre-M arc de Biasi ressaltou toda a riqueza de informações que se extrai da análise dos manuscritos de Flaubert.Tais materiais nos ensinam

[...] que nenhum fenômeno da escrita é interpretável de modo unilateral. A menor transformação nos rascunhos põe em jogo, na maioria das vezes, duas ou três variáveis, talvez mais: trabalho estilístico, elaboração simbólica, alusão sociohistórica, jogo de referência ao intertexto, jogo de palavras e pastiches, ou 
mesmo vestígios do inconsciente, sob a forma de lapsos, por exemplo (Bourdieu, apud Biasi, 1992, p. 110).

A genética textual permite, assim, descrever o processo extremamente complexo da gestação de uma obra, o trabalho da escrita. M as para uma explicação desse processo, o texto-pretérito e sua lógica interna não fornecem necessariamente a chave; será preciso sair do texto redacional e recorrer a uma estética que informe o processo. 0 ra, uma estética é sempre um fato social; ela define o belo e sua função em relação a uma sociedade. E dizer que o belo se opõe radicalmente à sociedade e a seus valores é ainda um ato social. Publicar é um ato eminentemente social, é entrar no domínio público. Jacques $\mathrm{N}$ eefs tem razão ao distinguir radicalmente a "crítica genética", que

[...] se aferra à textualidade em movimento de uma obra, pelo estudo de seus textos-pretéritos, de seus rascunhos, de suas versões diversas, da noção de "genético" tal como aparece, desde Goldmann, nos métodos sociológicos do "estruturalismo genético" ( $N$ eefs, 1990, p. 23).

Pierre-M arc de Biasi ressaltou com toda a razão que seria preciso distinguir a dimensão genética da dimensão crítica:

A genética textual não comporta nela mesma um critério de avaliação crítica, mas abriga um duplo objetivo, que consiste, de um lado, em tornar tecnicamente legível e analisável o texto- pretérito, sua evolução, seu trabalho interno até sua forma definitiva, e, de outro lado, em reconstruir a lógica dessa gênese (Biasi, 1985, p. 468).

E Biasi continua afirmando que o segundo aspecto - o estudo da gênese - só pode ser atingido quando se mobiliza "um caminho crítico seletivo", isto é, quando se parte de um modelo de explicação extratextual. Existem modelos de explicação social mais sutis que os propiciados pelo estruturalismo genético goldmaniano, e que levam em conta, sobretudo, o fato extremamente importante da autonomização da produção cultural ao longo do século XIX. 


\section{A teoria do campo literário}

Eu me refiro, é claro, à teoria do campo literário. Pierre Bourdieu supõe, por meio dela, que

[...] a análise das sucessivas versões de um texto lograria sua plena força explicativa se visasse a reconstruir [...] a lógica do trabalho de escrita entendido como pesquisa levada a cabo sob o constrangimento estrutural do campo e do espaço dos possíveis que Ihe é inerente (Bourdieu, 1992, pp. 277-278).

Compreende-se melhor, segundo ele,

[...] as hesitações, os arrependimentos, os retornos, quando se sabe que a escrita, navegação perigosa em um universo de ameaças e perigos, é também guiada, em sua dimensão negativa, por um conhecimento antecipado da recepção provável inscrita em estado de potencialidade no campo; que [...] o escritor, tal como o concebe Flaubert, é aquele que se aventura fora das rotas balizadas do uso ordinário e que se revela um expert na arte de achar a passagem entre os perigos que são os lugares comuns, as “idéias prontas", as formas convencionais (I dem, ibidem).

A genética textual e a genética social não me parecem, portanto, estar atadas por relações de exclusão, mas por liames de complementaridade. Importa apenas que haja algum entendimento em torno da noção de social, em vez de se tomar como ponto de partida uma dicotomia indivíduo-sociedade. Sendo o indivíduo o social incorporado, seria inútil partir da idéia de que existem domínios de exterritorialidade em relação ao mundo social. Essa complementaridade entre genética textual e genética cultural foi demonstrada por H enri M itterrand, ao salientar o propósito de Zola, que nas primeiras linhas de um esboço, escrito com relativa espontaneidade, já se revelava o contato mais direto entre o discurso social assumido por Zola e as concepções coletivas do período contemporâneo. E mais, ele constata que, no decorrer do processo de escritura, as obras, de início objetos, transformavam-se em sujeitos. Por meio da dinâmica da escrita, seria perceptível de imediato essa interação entre o social e o estético (M itterrand, 1989, pp. 147-162). Pierre-M arc de Biasi sublinha, por sua vez, que do real ao texto a relação permanece, na melhor das hipóteses, conjuntural. N ão se pode, portanto, 
[...] minimizar as riquezas desta imensa fonte de informações que são os documentos de redação da obra. É um espaço no qual se pode observar de frente a maneira pela qual o escritor inventa, inova, faz suas escolhas, no qual se enxergam suas estratégias as mais secretas de defesa e de ataque. Para um estudo das condições sociais de possibilidade, [a seus olhos] é uma mina... (Biasi, 1992, p. 110)

... uma prova suplementar da complementaridade das duas genéticas. 0 que impressiona deverasé a valoração, de uma e de outra parte, da dimensão genética. Pierre B ourdieu conclama a que se trabalhe de "forma articulada [...] para se atrelar a uma verdadeira teoria da produção literária" (apud Idem, p. 111). 0 conceito de gênese já aparecia no subtítulo de sua obra L es règles del'art. A finalidade da análise científica é, a seu ver, "iluminar aquilo que torna a obra de arte necessária, isto é, a fórmula informadora, o princípio gerador [...]" (Bourdieu, 1992, p. 14).

Por meio do personagem Frederico, de L'éducation sentimentale, e da descrição de sua posição no espaço social, Flaubert expõe, segundo Bourdieu, "a fórmula geradora que está na raiz de sua própria criação romanesca" (I dem, p. 55). Somente uma análise da gênese do campo literário no qual se constituiu o projeto flaubertiano pode levar a uma compreensão verdadeira, bem como da fórmula geradora que está na raiz da obra e do trabal ho graças ao qual Flaubert "logrou consumá-la, ao objetivar, no mesmo movimento, essa estrutura geradora e a estrutura social de que ela é o produto" (Idem, p. 76).

A originalidade da teoria do campo literário, elaborada por Pierre Bourdieu desde meados dos anos de 1960, mas apresentada de maneira sistemática em sua obra de 1992, L es règles de l'art, consiste em não separar o texto do contexto, como sugerira Barthes em seu célebre artigo "H istória ou literatura", e ao mesmo tempo respeitar o princípio da autonomia, a autonomização dos campos específicos constituindo de fato um processo social importante. Bourdieu procura assim se distanciar de uma abordagem crítica voltada apenas à obra - ajustada a uma estética interna " que pretende tratar a obra como um sistema, capaz de abranger em si mesmo, em sua coerência, os princípios e as normas de seu deciframento" (1966, p. 905) e que ainda se Ihe confere a aparência de irredutibilidade. Essa abordagem é, segundo ele, tributária de uma pré-noção - a obra hipostasiada - e fica impedida assim de reinserir a obra no sistema inclusivo do qual ela faz parte.

É a estética externa - segundo a terminologia de Bourdieu - que se empenha em reinserir as obras em uma estrutura mais vasta, esforçando- 
se, na maioria das vezes ao preço de uma alteração redutora, por situar a obra em relação com as condições econômicas, sociais e culturais da cria ção artística. Essa abordagem não dialética, que enxerga na obra um reflexo imediato de uma dada situação socioeconômica, subestima entretanto a existência de novos intermediários entre essa situação e a variada produção cultural.

Para Bourdieu, as obras literárias e artísticas não podem ser expressão de uma classe social. Ele recusa o conceito substancialista de classe; e rechaça ao mesmo tempo a dicotomia "indivíduo" versus "sociedade", dois conceitos que lhe parecem pré-científicos.

A teoria do campo, que não se apóia no postulado de uma sociedade global, concebe um espaço social constituído por campos relativamente autônomos, e supõe uma série de rupturas com a teoria marxista.Trata-se, primeiro, da ruptura com o conceito de classe social, da ruptura "com a tendência a privilegiar as substâncias - neste caso, os grupos reais dos quais pretende- se definir a quantidade, os limites, os membros etc. - em detrimento das relações" (Bourdieu, 1984, p. 3), mas também da ruptura com a idéia de uma determinação econômica "em última instância" , " [...] com o economicismo que leva a reduzir o campo social, espaço multidimensional, apenas ao campo econômico, às relações de produção econômica, assim constituídas em coordenadas da posição social" (Idem, ibidem). Se B ourdieu deve a M arx a categoria do capital, ele não o reduz de forma alguma à dimensão econômica, pois faz distinções entre o capital econômico, o cultural, o social e o simbólico.

O que caracteriza a estrutura de um campo? Há de início um certo número de invariantes (formais) que estão presentes em todos. $\mathrm{H}$ á sempre uma relação antagônica entre aqueles que Bourdieu chama, na linha da sociologia religiosa de $\mathrm{M}$ ax Weber, de "ortodoxos" e de "heréticos". O s ortodoxos, " que, num determinado ponto das relações de força, monopolizam (mais ou menos completamente) o capital específico característico de um campo, são inclinados a adotar estratégias de conservação" (B ourdieu, 1980, p. 115). 0 s menos dotados de capital simbólico, em contrapartida, "tendem a adotar estratégias de subversão - aquelas da heresia" (I dem, ibidem). A pesar dos antagonismos, há também interesses fundamentais implícitos que todos os agentes do campo compartilham e que estão ligados à sua própria existência. Aquele que entra em luta entra no jogo e reconhece como válidos os móveis em disputa. Tampouco se poderá esquecer que o capital simbólico guarda seu valor no interior de um campo, sendo 
pois específico desse campo e não mais conversível em outro. Bourdieu explica dessa maneira o fracasso de $\mathrm{C}$ ardin, ao tentar transferir para 0 campo da alta cultura um capital acumulado na alta costura. D a mesma forma, um capital acumulado no campo da política não será imediatamente eficaz no campo literário.

Ao se admitir a existência de invariantes, de traços estruturalmente equivalentes, se não idênticos, reconhece-se que o campo literário é um campo como outro qualquer, o que vai "contra a tendência de pensar que os universos sociais nos quais se produzem tais realidades de exceção, como a arte, a literatura ou a ciência, possam ser a tal ponto totalmente diferentes, e diferentes sob todos os aspectos" (Bourdieu, 1987, p. 168). $M$ as todos os traços estruturalmente invariantes se revestem de uma forma específica no campo literário. 0 capital simbólico do campo literário, como capital de reconhecimento, continua B ourdieu, "não se mede nem pelo sucesso comercial - muito pelo contrário -, nem pelo pertencimento a academias, pela obtenção de prêmios etc., nem mesmo pela simples notoriedade que, se adquirida por vias tortuosas, pode inclusive desmerecer". Trata-se de um tipo de capital simbólico muito particular, embora nunca deixe de ser um capital simbólico. Segundo Bourdieu, a noção de campo garante o meio de "apreender a particularidade na generalidade, $\mathrm{e}$ a generalidade na particularidade" (I dem, ibidem).

Poder-se-ia censurar a teoria do campo por enfatizar demais os limites que o separam da sociedade global. "A noção de campo autônomo", assim estimava Jacques Dubois, "leva a teoria a pensar o social e suas determinações apenas como exterioridade, um pouco como se a instituição não tivesse nada a ver com o social, ou não contribuísse para fazê-lo existir" (Dubois, 1978, p. 38). N a perspectiva de Bourdieu, as interferências sociais não agem de maneira imediata sobre os agentes do campo; elas são reinterpretadas conforme a lógica dele: "Toda influência e todo constrangimento exercidos por uma instância externa ao campo intelectual são sempre refratados pela estrutura desse campo: é assim por exemplo que a relação que um intelectual mantém com sua classe de origem ou de pertencimento é mediada pela posição que ele ocupa no campo intelectual, e em função da qual ele se sente autorizado a reivindicar tal pertencimento (com as escolhas que se the associam) ou inclinado a repudiá-lo e a dissimulá-lo como algo humilhante". Assim, "os determinismos só se tornam determinação especificamente intelectual quando reinterpretados no bojo de um projeto criador, eis a lógica 
específica do campo intelectual" (Bourdieu, 1966, p. 905). E dirá posteriormente:

A sociologia da arte ou da literatura que liga diretamente as obras à posição no espaço social (a classe social) dos produtores ou de seus clientes, sem considerar sua posição no campo de produção [...] escamoteia tudo que a obra deve ao campo e à sua história, quer dizer, muito precisamente, 0 que faz dela uma obra de arte, de ciência ou de filosofia (Bourdieu, 1980, pp. 117-118).

B ourdieu não nega as interferênciaspolíticas, sociais e econômicas; mas essas interferências são, segundo ele, sempre mediadas. N um estudo publicado na revista $S$ colies, ele ressalta que o campo intelectual está inserido num tipo específico de campo político: "O campo intelectual, por maior que seja sua autonomia, é determinado em sua estrutura e sua função pela posição que ocupa no interior do campo do poder" (1977, p. 15).

B ourdieu deverá mais tarde especificar essa posição. 0 s campos de produção cultural ocupam uma posição dominada no campo do poder, ou, em outras palavras, os artistas e os escritores constituem uma fração dominada da classe dominante. Eles são dominantes porque detêm um capital cultural que Ihesconfere poder e privilégios. $M$ as, em suas relações com os detentores do poder político e econômico, são dominados. N ão se trata de uma dominação pessoal, como no tempo do mecenato, mas de uma dominação estrutural, exercida por mecanismos gerais, como os do mercado. Essa posição de dominantes dominados explica, segundo Bourdieu, a ambigüidade das tomadas de posição dos intelectuais: "R evoltados contra os que designam de 'burgueses', eles são solidários com a ordem burguesa, como se constata em todos os períodos de crise em que seu capital específico e sua posição na ordem social são verdadeiramente ameaçados" (Bourdieu, 1987, p. 173). Se o campo literário não pode nunca abstrair por completo o campo do poder, assiste-se no entanto a um processo de autonomização progressiva em relação aos constrangimentos externos, "quer as censuras morais e os programas estéticos de uma I greja empenhada em proselitismo, quer os controles acadêmicose as encomendas de um poder político inclinado a enxergar na arte um instrumento de propaganda" (B ourdieu, 1971, p. 51). 0 modelo do campo literário permite compreender as relações internas entre dominantes e dominados como relações de força e de luta, o que implica uma desconfiança quanto às auto-representações ideológicas. Esse tipo de abordagem comporta (e exige) um senso 
agudo do aspecto estratégico. Trata-se de apreender sobretudo a relação entre tomadas de posição e posições no campo, sem por isso negligenciar os aspectos formais. A teoria do campo literário não se reduz nem ao estabelecimento de uma relação direta dos produtos culturais com a biografia individual ou com a classe social, nem à análise interna ou intertextual:"É preciso fazer tudo isso junto" (Bourdieu, 1987, p. 175).

Pierre Bourdieu postula uma homologia entre 0 espaço das obras em suas diferenças, seus desvios, e o espaço dos produtores e das instituições de produção (I dem, ibidem). Às diferentes posições no campo de produção (gênero, status do gênero, lugar de publicação), bem como às posições ocupadas no campo, corresponderiam outras assumidas no espaço dos modos de expressão (formas literárias e artísticas, alexandrinos ou outras métricas, rima ou verso livre, temas e toda sorte de índices formais).

Para se ler adequadamente uma obra na singularidade de sua textualidade é preciso lê-la consciente ou inconscientemente em sua intertextualidade, isto é, por meio do sistema de desvios pelo qual ela se situa no espaço das obras contemporâneas; mas essa leitura diacrítica é inseparável de uma apreensão estrutural do autor correspondente, que é definido [...] pelas relações objetivas que determinam sua posição no espaço de produção [...] (I dem, ibidem).

\section{Referências Bibliográficas}

BARTHES, R oland. (1960), “H istoire et littérature: à propos de R acine”. A nnales ESC, III, maio-jun.

BIASI, Pierre-M arc de. (1985), "Vers une science de la littérature: I'analyse des manuscrits et la genèse de l'oeuvre". E ncydopedia universalis.

(ed.). (1992), "Tout est social". M agaz ine L ittéraire, 303, out.

Boschettı, Anna. (1985), Sartre et "L esT emps M odernes" . Paris, M inuit.

Bou R DIEU , Pierre. (1966), “C hamp intelectuel et projet créateur”. L esTemps M odernes, 246, nov.

. (1971), “Le marché des biens symboliques”. L'A nnée Sodiologique, 22. . (1977), “C hamp du pouvoir, champ intellectuel et habitus de classe”. Scolies, 1. . (1980), "Q uelques propriétés des champs” . Q uestions de Sociologie, Paris, M inuit. . (1984), "Espace social et genèse de classe”. A des de la R echerche en Sciences Sodales, 52-53, jun.

. (1987), C hoses dites. Paris, M inuit. 
. (1992), L es règles de l' art: genèse et structure du champ littéraire. Paris, Seuil.

Brunel, P.; M Adelén AT, D.; Gliksohn , J. M . \& COUnTY, D. (1977), L a critiquelittéraire. Paris, PU F.

C HAR LE, C hristophe. (1979), L a crise littéraire à I'époque du naturalisme: roman-theâtrepolitique. Paris, P.E.N.S.

C OM PAGN ON , A ntoine. (1998), L e démon de la théorie: littérature et sens commun. Paris, Seuil.

Cou sIn ,V ictor. (1849), 0 euvres (Q uatrième série, Littérature). Paris, Pagnerre, t. I.

Debray - Gen ette, R aymonde. (1979), E ssais de critique génétique. Paris, Flammarion.

DIR KX, Paul. (2000), Sodologie de la littérature. Paris, Armand Colin.

D u Bo IS, Jacques. (1978), L'institution de la littérature. Bruxelas, Labor.

EsPAgn E, M ichel. (1990), "La référence allemande dans la fondation d'une philologie française". In: $\&$ W ER NER, M ichael (eds.). Philologiques I. C ontribution à I'histoire des disaiplines littéraires en $\mathrm{F}$ rance et en $\mathrm{A}$ llemagne au $\mathrm{XIX}$ e siècle. Paris, É ditions de la M aison des Sciences de l'H omme.

G ALST ER , Ingrid. (1986), L e théâtre de J ean-Paul Sartre devant ses premiers critiques. Paris, Jean-M ichel Place.

Gen ette, Gérard. (1963), E ssais de linguistique générale. Paris. . (1966), Figures I. Paris, Seuil. . (1972), F igures III. Paris, Seuil. . (1983), “Transtextualité”. M agaz ine Littéraire, 192, fev.

Goldm An N , Lucien. (1964), Pour une sodiologie du roman. Paris, Gallimard. . (1971), L e D ieu caché. Paris, G allimard.

Grotzer, Pierre. (1977), Existence et destinée d'A Ibert B éguin. N euchâtel, La Baconnière. G UISSAR D, Lucien. (1983), “U n critique spirituel,A lbert Béguin”. M agaz ine L ittéraire, 192, fev.

JAR R ETY, M ichel. (1988), L a critique littéraire française au X X e siède. Paris, PU F (coleção "Q ue sais-je?").

JURT, Joseph. (1989), “D e l'analyse immanente à I'histoire sociale de la littérature: à propos des recherches littérai res en Allemagne depuis 1945". A ctes de la R echerche en Sciences Sodales, 78: 94-101, jun.

. (1991), “H elvetia mediatrix?”. In: Rü ck, Peter (ed.). G renz erfahrungen. Schweizer $W$ issenschaftler, Journalisten und $K$ ünstler in D eutschland. M arbourg, Basilisken Presse, pp. 199-212.

Lan SO n, G ustave. (1965), “La méthode de l'histoire littéraire”. I n: Peyre, H enri (ed.). E ssais de méthode, de critique et d'histoire littéraire. Paris, H achette (1. ed. 1910). M ASSIS, Henri \& TAR DE, Alfred de [A gathon]. (1911), L'esprit de la nouvelle Sorbonne. Paris, $M$ ercure de France. 
M itter and, Henri. (1989), "C ritique génétique et histoire culturelle: les dossiers des R ougon-M acquart". In: H AY, Louis (ed.). L a naissance du texte. Paris, José C orti, pp. 147-162.

N eefs, Jacques. (1990), “C ritique génétique et histoire littéraire”. In: BéHAR, H . \& Fayolle, R . (eds.). L'histoire littéraire aujourd'hui. Paris, A rmand Colin.

Ponton, R émy. (1990), “Durkheim et Lanson”. In: Espagne, M ichel \& W erner, $M$ ichael (eds.). Philologiques I. C ontribution à I'histoire des disciplines littéraires en F rance et en $A$ llemagne au X IX ${ }^{\mathrm{e}}$ siède. Paris, Éditions de la M aison des Sciences de I'H omme, pp.253-286.

RaYMOND, M arcel. (1975), "L'école de Genève: mythe ou realité?" [entrevista]. M icromégas, II, 1, jan.-abr.

R EICH LER , Claude. (1987), "Jean Starobinski et la critique genevoise”. C ritique, 481482: 606-611, jun.-jul.

SARTR E, Jean-Paul. (1946), “Q u'est-ce que la littérature?” . L esTemps M odernes, 17-22. . (1948), Situations, II. Paris, Galimard, pp. 77-78. . (1967), Q uestions de méthode. Paris, Gallimard.

SicAR D, M ichel. (1976), L a critique littéraire de Jean-Paul Sartre. Paris, M inard.

StAro bIN SK I, Jean. (1975), “L'école de Genève: mythe ou realité?”. M icromégas, II, 1, jan.-abr.

StEIn WACHS, Burkhart. (1990), “Les perspectives d'une'science de la philologie'”. In: ESPAGN E, M ichel \& W ER N ER , M ichael (eds.). P hilologiques I. C ontribution à l'histoire des disáplines littéraires en $\mathrm{F}$ rance et en $\mathrm{A}$ llemagne au $\mathrm{XIX}{ }^{\mathrm{e}}$ siècle. Paris, Éditions de la $M$ aison des Sciences de I'H omme, pp. 269-275.

T ADIÉ, Jean-Y ves. (1967), L a critique littéraire au X X e siède. Paris, Belfond.

Thibaud det, A lbert. (1966), P hysiologie de la critique. Paris, N izet.

W ER N ER , M ichael. (1990), “À propos de l'évolution historique des philologies modernes: I'exemple de la philologie romane en Allemagne et en France" . In:

\& Espagne, Michel (eds.). Philologiques I. C ontribution à I'histoire des disciplines littéraires en F rance et en A llemagne au XIX ${ }^{\mathrm{e}}$ siède. Paris, Éditions de la M aison des Sciences de l'H omme. . (1994), "La place relative du champ littéraire dans les cultures nationales: quelques remarques à propos de l'exemple franco-allemand" . In: $\&$ ESPAGNE, M ichel (eds.). P hilologiques III . Q u'est-œ qu'une littérature nationale? A pproche pour une théorie interculturelle du champ littéraire. Paris, Éditions de la M aison des Sciences de l'H omme, pp. 15-30.

W In ock, M ichel. (1987), C hronique des années soixante. Paris, Seuil. 


\section{Resumo}

0 texto efetua um balanço histórico dos estudos literários franceses pelo prisma de suas principais correntes e autores: a abordagem da Escola de G enebra, que concebia 0 ato crítico como encontro entre a consciência crítica e o projeto criativo; a proposta sartriana de explicar a especificidade das obras literárias pelos condicionamentos sociais e psicológicos; o estruturalismo genético de L. Goldmann, cujo conceito explicador da literatura era o grupo social; a teoria das formas literárias, que pretendia isolar o texto como forma de seu contexto; a crítica genética, voltada para a dinâmica do processo criativo pelo estudo dos manuscritos; a teoria do campo literário de Bourdieu, que restaura a autonomia da literatura como fato social com base na lógica interna do campo.

Palavras-chave: Estudos literários na França; Positivismo; Estruturalismo genético; Textualismo; C ampo literário.

\section{Abstract}

The article addresses a historical state of the art concerning the French literary studies, stressing its main trends and authors: the Geneva school approach, that conceived the critical act as encounter between the critical conscience and the creative project; the Sartre proposal to explain features of the literary works through social and psychological constraints; L. Goldmann's genetic structuralism, whose explaining concept about literature was the social group; the theory of literary forms which intended to isolate the text as form from its context; the genetic criticism, focusing the dynamics of the creative process based in the study of manuscripts; Bourdieu's theory of literary field, that recovers the autonomy of literature as a social fact embedded within the internal design and logic of the field.

Keywords: Literary studies in France; Positivism; G enetic structuralism; Textual analysis; Literary field.

Joseph Jurt é professor de literatura francesa na U niversidade A lbert Ludwig, Fribourg-en-

Bisgau. 